\title{
TRANSFERRIN VARIATION BETWEEN MOTHER AND FETUS IN THE MARSUPIAL, MACROPUS EUGENII
}

\author{
MARILYN B. RENFREE* AND C. H. TYNDALE-BISCOE \\ Department of Zoology, The Australian National University, \\ Canberra, A.C.T. 2600, Australia
}

(Received 10th Fuly 1972)

The placenta of the tammar wallaby, like that of most marsupials, is formed by close apposition of the yolk-sac membrane to the uterine epithelium. The yolksac fluid is rich in a variety of substances such as amino acids, glucose and protein which change quantitatively and qualitatively throughout gestation, the most marked changes occurring after attachment of the membrane to the uterus (Renfree, 1970).

Since many of the proteins resemble maternal proteins, they may have been transferred unchanged after attachment; conversely, they may have been synthesized by the embryo and the similarities may be due to the genetic similarities of the embryo and its mother. We have examined these two possibilities in the $\beta$-globulin proteins of yolk-sac fluid. The transferrins in this moiety of serum can be detected by virtue of their capacity to bind Fe. In adult tammar wallabies, Macropus eugenii, serum transferrin occurs in two forms with different electrophoretic mobilities. All tammars on Kangaroo Island, South Australia, have one form while tammars on Garden Island, Western Australia, have a slower moving form (Kirsch, 1967). These two populations have been genetically isolated for at least 9000 years and probably considerably longer (TyndaleBiscoe, 1972). The design of the experiment was to transfer early blastocysts from females of one race to the appropriately stimulated uteri of females of the other race by the technique previously described (Tyndale-Biscoe, 1970), and to sample yolk-sac fluid 23 days later and compare it to serum from the donor and recipient females. If transferrin crosses the yolk sac membrane, the form detected should resemble the foster mother's but if it is synthesized by the embryo, it should resemble the donor race's transferrin. We describe here the identification of transferrin in yolk-sac fluid of both races and the results of successful transfer of Garden Island blastocysts to Kangaroo Island recipients.

Samples of yolk-sac fluid and maternal serum were collected as already described (Renfree, 1970). Fetal blood was collected on Day 23 (Day 0= the day that resumption of development of delayed embryos was induced by removal of the pouch young) directly from the vitelline vessels of the yolk sac into heparinized microcapillary tubes after removal of the embryo and mem-

* Present address: Department of Zoology, The University of Tennessee, Knoxville, Tennessee 37916, U. S. A. 
branes from the uterus. The tubes were sealed, centrifuged to separate the plasma and stored at $-15^{\circ} \mathrm{C}$ until analysis. In addition to the samples taken from the transferred embryos, fluids were collected from five normal Kangaroo Island embryos on Day 17, from fifteen on Day 23, and from one normal Garden Island embryo on Day 23.

Transferrin was identified by autoradiography after electrophoresis. Radioactive iron was obtained from The Radiochemical Centre, Amersham, Bucks., as ${ }^{59} \mathrm{FeCl}_{3}$, and between 0.5 and $1.0 \mu \mathrm{Ci}$ of ${ }^{59} \mathrm{Fe}$ was incubated with each sample of serum or yolk-sac fluid. Samples were separated by acrylamide gel electrophoresis (Davis, 1964), and allowed to run until the marker dye had reached the bottom of the gel. They were sliced in half longitudinally, and one half was stained with Amido Black. The other half was immediately placed on thin plastic overlying Kodirex (Kodak) medical X-ray film, held firmly by masking tape with the flat surface of the gel down, and placed in a light-proof box at $-20^{\circ} \mathrm{C}$ for 3 to 4 days. Developed films were compared with stained halves to locate the radioactive band.

Aliquots of serum, fetal plasma and yolk-sac fluid were separated electrophorectically alone, and others were mixed together before electrophoresis to ascertain similarities and differences in the mobilities of the transferrin types.

Sera from the two island populations had a single transferrin and in mixtures of sera from fifteen adults of each race, two transferrin bands were resolved, confirming the observations of Kirsch (1967) on starch gel.

Transferrin was detected in all the yolk-sac fluids sampled on Day 23, but in none of those sampled on Day 17. It is possible that transferrin is present in vesicle fluid but is too dilute to be detected by this method. Transferrin was also detected in fetal plasma in all the six samples tested, and when mixed with yolk-sac fluids from the same embryos, a single band was still resolved, indicating that, in this system of separation, there was only one transferrin in fetal plasma and yolk-sac fluid.

Three of the twelve blastocysts transferred grew to advanced embryos, but only one was of different genetic type from the recipient, although all three completed their embryonic development in a foster uterus.

Transferrins in the yolk-sac fluid had different electrophoretic mobilities from their respective maternal serum transferrins and when mixed together, two distinct bands were resolved (Plate 1). Kangaroo Island yolk-sac fluid and Garden Island yolk-sac fluid transferrins had identical electrophoretic mobilities and when mixed together, a single band only was detected. The result was the same from the three successfully transferred blastocyts-each embryo had a different transferrin from the maternal type but the transferrin from yolk-sac fluid always had the same electrophoretic mobility regardless of the origin of the embryo or the uterine environment in which it was placed.

We conclude that the single transferrin found in the yolk-sac fluid and fetal plasma of Macropus eugenii is of fetal origin and has not been transferred from the maternal circulation.

This study was supported by a grant for marsupial research from the Commonwealth Scientific and Industrial Research Organization. 


\section{PLATE 1}

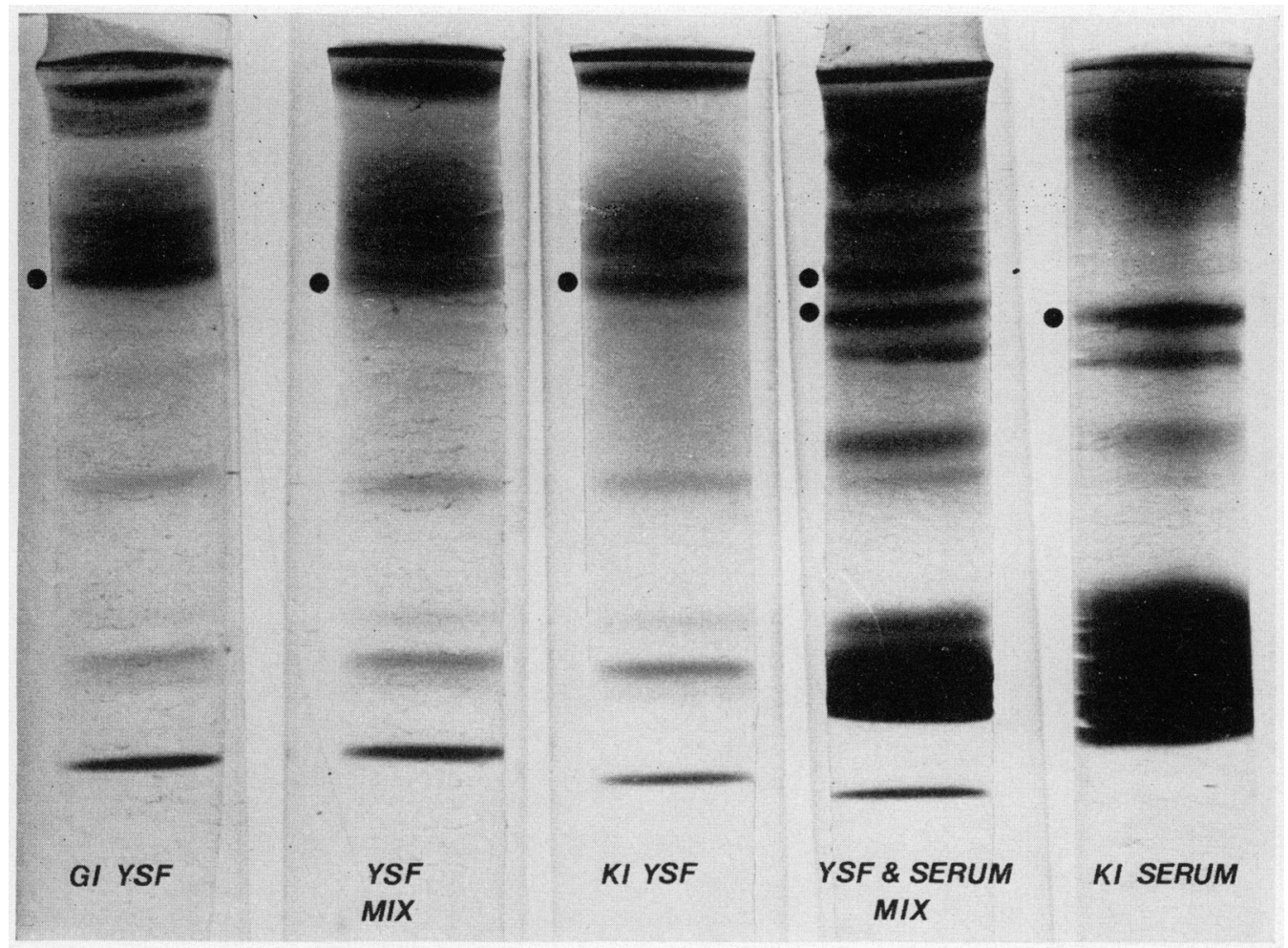

Representative disc electrophoretic patterns of serum and yolk-sac fluid (YSF) from Kangaroo Island (KI) and Garden Island (GI) races of wallabies, separated both as pure samples and as mixtures. Proteins which bound ${ }^{59} \mathrm{Fe}$ are shown by a dot. Two iron-binding proteins were only detected in mixtures of serum with yolk-sac fluid regardless of genetic origin, and in mixtures of serum from the two island populations. 


\section{REFERENCES}

DAvis, B. J. (1964) Disc electrophoresis. II. Method and application to human serum proteins. Ann. N.Y. Acad. Sci. 121, 404.

KIRscr, J. A. W. (1967) Serological characterization of the Parma wallaby, Macropus parma, Waterhouse, 1846. Aust. F. Sci. 29, 430.

Renfree, M. B. (1970) Protein, amino acids and glucose in the yolk-sac fluids and maternal blood sera of the tammar wallaby, Macropus eugenii (Desmarest). F. Reprod. Fert. 22, 483.

Tyndale-Biscoe, G. H. (1970) Resumption of development by quiescent blastocysts transferred to primed, ovariectomized recipients in the marsupial, Macropus eugenii. F. Reprod. Fert. 23, 25.

Tyndale-Biscoe, G. H. (1972) Life of marsupials. Edward Arnold, London. 